\title{
DISIDENCIA ÉTICA Y DESOBEDIENCIA CIVIL
}

\author{
CARLOS GOMEZ SÁNCHEZ \\ Departamento de Filosofia Moral y Politica. UNED
}

\section{Prehistoria de un concepto}

A un concepto siempre se le pueden encontrar antecedentes. Si la noción de "desobediencia civil" se forja en Estados Unidos a mediados del siglo XIX, su prehistoria es, sin embargo, muy dilatada. Por mencionar sólo algunos ejemplos ilustres, quizá el primero que podamos asociar a la cuestión sea el de Antígona. Sin entrar a discutir las múltiples interpretaciones que su figura ha suscitado, quizá sea oportuno recordar cómo Antígona, a fin de enterrar a su hermano Polinices, opone a las leyes de la ciudad otras "leyes no escritas", a las que estima es preciso obedecer primero: «No pensaba - le objeta a Creonte- que tus proclamas tuvieran tanto poder como para que un mortal pudiera transgredir las leyes no escritas e inquebrantables de los dioses" 1 . Esta desobediencia a la ley la enfrenta a los gobernantes y a sus conciudadanos. Pero Antígona sigue los dictados de su conciencia y arrostra la muerte, "porque con mi piedad he adquirido fama de impía 2 .

De impiedad es precisamente de lo que se trata en la acusación que Meleto, Anito y Licón formularon contra Sócrates, tal como lo recoge Platón en su Apologia. También Sócrates apela a un principio superior y acepta el castigo:

Atenienses: obraría yo indignamente, si, al asignarme un puesto los jefes que vosotros elegisteis para mandarme en Potidea, en Anfipolis y en Delion,

1 Sofocles, Antigona, 450-455, en Tragedias, introd. de J. S. Lasso de la Vega, trad. de A. Alamillo, Gredos, Madrid, 1981, 265.

2 Ibid., 924, ed. cit., p. 283. 
decidí permanecer como otro cualquiera allí donde me colocaron y corrí, entonces, el riesgo de morir, y en cambio ahora, al ordenarme el dios, según he creldo y aceptado, que debo vivir filosofando y examinándome a mi mismo y a los demás, abandonara mi puesto por temor a la muerte o a cualquier otra cosa [...]. Yo, atenienses, os aprecio y os quiero, pero voy a obedecer al dios más que a vosotros ${ }^{3} . »$

Así pues, durante mucho tiempo, lo que retrospectivamente se pueda considerar como antecedente de la "desobediencia civil», ejemplos paradigmáticos de un conflicto renovado en diferentes formas y circunstancias, se solía amparar en el concepto de leyes divinas o naturales que, aunque no escritas, están por encima de las proclamadas por los hombres. Las leyes positivas han de concordar o, al menos, no oponerse a aquéllas, si quieren ser legítimas, por lo que, en caso de discrepancia, la ley natural goza de prioridad ética.

Estas tensiones y estos planteamientos sirvieron de base a muchas discusiones durante la Edad Media y el mundo moderno, como, por ejemplo, las mantenidas a propósito de la legitimidad, en determinadas circunstancias, del derecho de rebelión frente al opresor e, incluso, el tiranicidió. Pero, como dećamos, es a mediados del siglo pasado cuando se acuña el término, asociado desde entonces a la vida y obra de Thoreau.

\section{Henry David Thoreau}

Henry Thoreau (Concord, Massachusetts, 1817) es una figura peculiar dentro del liberalismo americano, que resulta nuclear para nuestra cuestión. Y ello no sólo por la radicalidad con la que defendió sus posiciones, sino por el hecho de hacerlo dentro de un sistema liberal-democrático, la legitimidad de cuyas leyes parece más sólida que la de otros regímenes políticos, lo que agudiza los perfiles del conflicto y le otorgan mayor actualidad.

Hemos encuadrado a Thoreau dentro del liberalismo, aunque habría enseguida que advertir, como indica J. J. Coy en el estudio preliminar a Desobediencia civil y otros escritos, que, en realidad, Thoreau resulta difícilmente clasi-

3 Platón, Apología de Sócrates, 28d-e y 29d, en Diálogos. I, trad. de J. Calonge, Gredos, Madrid, 1981, 166-168.

4 Cfr. A. HoRTAL, "Desobediencia civil", en M. VIDAL, Conceptos fundamentales de ética teológica. Trotta, Madrid, 1992, 709-723, especialmente 709-712. 
ficable, poco convencional, y que su talante está más cerca del libertarismo que del liberalismo tradicional. En ese sentido es en el que habría que entender la provocativa declaración con la que comienza su escrito sobre la «Desobediencia civiln:

Acepto de todo corazón la máxima: «El mejor gobierno es el que gobierna menos», y me gustaría verlo puesto en práctica de un modo más rápido y sistemático. Pero al cumplirla resulta, y así también lo creo, que «el mejor gobierno es el que no gobierna en absoluto"; $y$, cuando los hombres estén preparados para él, ése será el tipo de gobierno que tendrán 5 .

Antiimperialista, en el momento del expansionismo norteamericano de mediados del siglo XIX, Thoreau se opuso a la guerra con México (1846-1848), promovida por intereses económicos y por el afán de ampliar los territorios en los que la esclavitud fuera legal, y se negó a pagar impuestos, para no colaborar con unos poderes públicos que mantenían la esclavitud.

Cuando una sexta parte de la población de un país que se ha comprometido a ser refugio de la libertad, está esclavizada, y toda una nación es agredida y conquistada injustamente por un ejército extranjero y sometida a la ley marcial, creo que ha llegado el momento de que los hombres honrados se rebelen y se subleven. Y este deber es tanto más urgente, por cuanto el país así ultrajado no es el nuestro, sino que el nuestro es el invasor ${ }^{6}$.

Defensor también de las minorias indias, Thoreau, a pesar de su radicalismo y de oponerse a la esclavitud y otras formas de opresión, no se incorporó al movimiento abolicionista, por desconfiar profundamente de toda acción colectiva. Su actitud es, ante todo, una actitud de rechazo ético ante lo que considera leyes injustas y una apelación a la conciencia ética de cada cual:

¿Debe el ciudadano someter su conciencia al legislador por un solo instante, aunque sea en la mínima medida? Entonces, ipara qué tiene cada hombre su conciencia? Yo creo que debiéramos ser hombres primero y ciudadanos después. Lo deseable no es cultivar el respeto por la ley, sino por la justicia. La única obligación que tengo derecho a asumir es la de hacer en cada momento lo que crea justo 7 .

5 H. D. THOREAU, «Desobediencia civil», en Desobediencia civil y otros escritos, estudio preliminar de J. J. Coy, trad. de M.a E. Diaz, Tecnos, Madrid, 1987, 29-57, cit., 29.

6 Ibid, 34.

7 Ibid., 31. 
Estos textos plantean algunas de las cuestiones centrales que hemos de debatir a propósito de la desobediencia civil. Pues no se dejará de objetar que, si cada cual hiciera en cada momento lo que estime en conciencia debe hacer, con independencia de lo que digan las leyes, quizá la convivencia social se haría imposible. Y que, aunque ciertos casos de desobediencia pueden comprenderse dentro de regímenes autoritarios, tal vez carezcan de justificación en los regimenes democráticos, en los que la soberanía radica en el pueblo, de donde extrae su legitimidad el poder legislativo. Aunque, por otra parte, habría que preguntarse en función de qué principios un ciudadano va a actuar en contra de su propia conciencia; y, por tanto, hasta qué punto y en qué medida la desobediencia civil puede estar justificada, si es que en algún caso lo está.

Antes de abordar esos problemas quizá no esté de más recordar que los escritos de Thoreau influyeron poderosamente en algunos hombres y movimientos relevantes del siglo XX, como la no violencia activa de $\mathrm{M}$. Ghandi o la lucha por los derechos civiles y contra la segregación racial de los negros en Estados Unidos, llevada a cabo en la década de los sesenta por Martin Luther King, que le llevaba a decir en su discurso I have a dream, pronunciado en el Lincoln Memorial de Washington, en 1963, cinco años antes de ser asesinado:

Ayer soné que llegará un día en que esta nación se levante y viva de acuerdo con el verdadero sentido de su credo, según el cual consideramos como verdad evidente que todos los hombres fueron creados iguales. Ayer soñé que llegará un día en que en las rojas colinas de Georgia, los hijos de los antiguos esclavos y los hijos de los antiguos esclavistas puedan sentarse juntos a la mesa de la fraternidad [...]. Con esta fe podemos extraer de las montanas de la desesperación la piedra de la esperanza. Con esta fe seremos capaces de transformar la aspera discordia de nuestra nación en una hermosa sinfonía de hermandad ${ }^{8}$.

A partir de entonces, e incluso dentro de las democracias modernas, no han dejado de sucederse movimientos de oposición a determinadas leyes y situaciones, como lo fueron en su día la protesta ante la guerra del Vietnam, más tarde las cadenas humanas en contra de la instalación de los euromisiles y, en la actualidad, los objetores de conciencia e insumisos al servicio militar, entre otros ejemplos, que no han hecho sino revitalizar el debate.

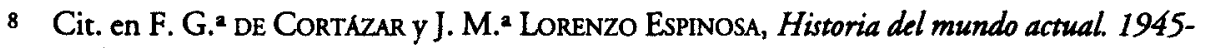
1995, II, Alianza, Madrid, 1996, 65-66. 
Para precisarlo, seguiré la formulación que del mismo han hecho algunos de los principales teóricos de nuestro días, como J. Rawls o J. Habermas.

\section{John Rawls: la desobediencia civil en el marco de una teoría neocontractualista de la justicia}

Se suele indicar que Una teoria de la justicia (1971), de J. Rawls, ha supuesto un giro decisivo en los planteamientos sobre temas ético-políticos del mundo anglosajón, hasta entonces dominados por la perspectiva utilitarista, tratando de revitalizar la teoría clásica del contrato social. Aclarada y reinterpretada en aportaciones posteriores como "Justicia como imparcialidad: política, no metafísica" (1985) ${ }^{9}$ o los artículos reunidos en "Justicia como equidad" ${ }^{10}$, Rawls ha querido elaborar una concepción político-moral aplicable a la organización social y política ubajo condiciones modernas". Sin intentar hacer aquí una apretada síntesis de su pensamiento, me limitaré a recordar algunas de las principales líneas de su construcción, en la medida en que ellas pueden enmarcar y arrojar luz al desarrollo de nuestro tema.

\subsection{El marco teórico}

El que la desobediencia civil esté justificada o no depende de la teoría de la obligación política que se mantenga. Rawls estima que una teoría apropiada para dar cuenta de esa obligación, en una democracia constitucional, es la teoría del contrato social, ampliamente entendida. Los principios de la justicia, según ello, habrán de entenderse como resultado del acuerdo hipotético al que llegarían los hombres de una determinada sociedad, colocados en la situación de la posición original - que es el análogo analítico de la noción tradicional de estado de naturaleza - y sometidos al velo de la ignorancia, lo que supone fuertes restricciones al conocimiento que se presume que las partes contratantes poseen, a fin de impedir que los principios de justicia sean elegidos en función de la concreta situación que cada persona habrá de ocupar en la estructura social. Se supone asimismo que estamos ante una realidad caracterizada por recursos

9 J. RAwLs, "Justicia como imparcialidad: política, no metafísicaw, Didlogo filosófico, 16 (1990), 4-32.

10 J. Rawls, Justicia como equidad. Materiales para una teorta de la justicia, trad. de M. A. Rodilla, Tecnos, Madrid, 1986. 
escasos, de forma que «la liberalidad de la naturaleza no es tan generosa como para hacer superfluos los esquemas cooperativos, ni tan severa como para hacerlos imposibles" " ${ }^{11}$, y que esas personas, consideradas libres e iguales, son capaces de actuar tanto razonable como racionalmente.

Por racional se entiende aquella acción que, persiguiendo determinados fines, es capaz de elegir los medios más adecuados para conducirnos a ellos, y por razonable el reconocimiento del ejercicio de los fines propios a la luz de los fines moralmente justificados de los otros. Para Rawls, aunque lo razonable requiere y presupone lo racional (sin concepciones del bien para mover o motivar a los ciudadanos no habría lugar para hablar de cooperación social), lo subordina a su vez, pues las distintas metas finales deben someterse a aquellos límites y términos de la cooperación social, susceptibles de ser aceptados por todos. Todo lo cual comporta una prioridad de lo razonable sobre lo racional o, si se quiere, de lo justo sobre lo bueno, a fin de hacer posible la convivencia y la cooperación en sociedades modernas, en las que reina una pluralidad de concepciones del Bien.

Como las fundamentaciones de éste son muy diversas según los grupos y personas que las defienden, la teoría de la justicia que se trata de alzar será, por tanto, una concepción "política, no metafísica", que se atiene a un firme principio de neutralidad frente a esas diferentes concepciones del bien. La cooperación social no puede basarse, en una sociedad plural, en teorías morales generales y comprehensivas, incapaces de generar el suficiente acuerdo, sino que es preciso recurrir a lo que Rawls denomina "consenso por solapamiento" (overlapping consensus), un acuerdo a partir del cual doctrinas distintas puedan afirmar las bases compartidas de los arreglos públicos.

Desde esos presupuestos, Rawls estima que los principios de justicia que se elegirían serían los siguientes: $10^{\circ}$ Toda persona debe tener un igual derecho al más extenso sistema total de libertades básicas iguales, compatible con un sistema similar de libertad para todos. $20^{\circ}$ Las desigualdades sociales y económicas deben estar ordenadas de tal forma que ambas estén: a) dirigidas hacia el mayor beneficio del menos aventajado; $\mathrm{y} b$ ) vinculadas a cargos $\mathrm{y}$ posiciones abiertas a todos bajo las condiciones de una equitativa igualdad de oportunidades. A esos principios va unido un orden lexicográfico, que se manifiesta en la

11 J. RAWrS, «La justificación de la desobediencia civil», en Justicia como equidad, cit., 90101 , cit., 91-92. 
prioridad del primer principio sobre el segundo, y de la segunda parte del segundo principio sobre la primera.

\section{2. ¿Estamos obligados a observar leyes injustas?}

Con esos planteamientos, Rawls piensa que, en algunas ocasiones, podemos estar obligados a observar ciertas leyes, pese a que las consideremos injustas. A partir del establecimiento de los principios de justicia en la posición original, los hombres han de avanzar hacia la elaboración de una constitución, acorde con dichos principios, y hacia la promulgación de leyes sujetas a las restricciones y procedimientos de la constitución. Considera asimismo que, al menos en las condiciones normales de un Estado moderno, la mejor constitución es alguna forma de régimen democrático que afirme la igual libertad política y haga uso de algún tipo de regla de la mayoría. Pero el proceso constitucional es un caso de lo que denomina justicia procedimental imperfecta, esto es, aquélla en la que, aun cuando dispongamos de un criterio de legislación justa, no queda garantizado que la legislación que se promulgue lo sea. Pese a ello, "tenemos entonces una obligación [...] de observar lo que la mayoría estatuye, aunque pueda ser injusto. De este modo resultamos obligados a observar leyes injustas, no siempre, por supuesto, pero sí siempre que la injusticia no sobrepase ciertos límites. Reconocemos que tenemos que correr el riesgo de sufrir los defectos del sentido de justicia de los demás” ${ }^{12}$.

Pero, ¿cuáles son esos límites y quién los marca? Pues, aunque se comprende lo que la argumentación de Rawls trata de señalar, parece que hay un conflicto no resuelto entre lo que Benjamin Constant - al que el propio Rawls hace referencia ${ }^{13}$ - llamaba la libertad de los antiguos y la libertad de los modernos, o aquella esfera de libertad negativa en la que nadie, ni el soberano, podría inmiscuirse, por más que el soberano no fuese una persona determinada que impusiera sus leyes a los demás, sino, como lo quería Rousseau, todo el pueblo.

Tratando de salvar, al mismo tiempo, la cooperación social y el respeto a las posiciones disidentes, Rawls insiste en que, «aunque el ciudadano se someta en su conducta al juicio de la autoridad democrática, no somete su juicio a ella. Y

12 Ibid., 93-94.

13 J. RAwLS, "Justicia como imparcialidad: política no metafísica", cit., 8. 
si a su juicio lo establecido por la mayoría sobrepasa ciertos límites de injusticia, puede el ciudadano pensar en la desobediencia civil» 14 . Lo cual nos aclara que quienes marcan esos límites por los que preguntábamos no son otros que cada uno de los ciudadanos, cuando así lo estimen en conciencia. $\mathrm{O}$, como indica explícitamente más adelante: «Cada uno tiene que decidir la cuestión por sí mismo, aunque, por supuesto, puede que decida erróneamente» 15.

\subsection{Concepto y justificación de la desobediencia civil}

Pues bien, por desobediencia civil Rawls entiende «un acto público, no violento y hecho en conciencia, contrario a la ley y habitualmente realizado con la intención de producir un cambio en las políticas o en las leyes del gobierno" ${ }^{16}$.

En primer lugar, la desobediencia civil descansa en una convicción política y no en la búsqueda del propio interés o del interés de un grupo. Se dirige al sentido de justicia de la mayoría, advirtiendo que, en la sincera opinión de los disidentes, no se están respetando las condiciones de la cooperación social.

En segundo lugar, aunque se infrinja una determinada ley, se respetan los procedimientos legales, puesto que el castigo por aquella violación se espera y se acepta sin resistencia, tratando de mostrar a la mayoría que la desobediencia es sincera. Su carácter no violento hace de ella, pues, la expresión de una convicción, una forma de discurso.

Rawls advierte que la no violencia puesta de manifiesto ahí es distinta de la no violencia como principio religioso o pacifista, pues aunque los que se embarcan en la desobediencia civil actúan muchas veces llevados, en última instancia, por esos principios, lo básico, en una sociedad democrática, es la apelación a la base moral de la vida pública -lo que conecta con su concepción "no metafísica» de la justicia—, hasta el punto de que, frente a lo defendido por determinadas corrientes pacifistas, el desobediente civil, si sus demandas son reiteradamente desatendidas, puede adoptar otras medidas más activas de resistencia.

14 J. RAwhs, "La justificación de la desobediencia civil», cit., 94.

15 Ibid., 100.

16 Ibid., 94. 
Para que la desobediencia civil, así entendida, pueda estar justificada ha de cumplir determinados requisitos. La desobediencia civil no es una acción política normal. Ha de entenderse que ya se han utilizado otros recursos y que sólo se emprende tras agotar éstos. Ha de referirse, además, a violaciones claras y substanciales de la justicia, lo que, para Rawls, quiere decir violaciones que atenten al primero de los principios de justicia y a la segunda parte del segundo principio (la referente a la igualdad de oportunidades), puesto que son más definibles y precisas que las referentes a políticas sociales y económicas y, de ser escuchadas las demandas, tienden a corregir asimismo las injusticias que se puedan producir en este otro tipo de cuestiones. En tercer lugar, la actitud del disidente ha de ser universalizable; es decir, el disidente ha de estar "dispuesto a afirmar que cualquier otro similarmente sujeto al mismo grado de injusticia tiene derecho a protestar de modo similar» 17.

Con estas restricciones, Rawls entiende no sólo que la desobediencia civil no tiene por qué provocar el caos social, como tantas veces se ha objetado, sino que «ejercida en la debida forma, es un dispositivo estabilizador en un régimen constitucional, un dispositivo que tiende a hacerlo más firmemente justo» 18 .

\section{Jürgen Habermas: la doctrina de los intereses generalizables y la desobediencia civil}

Cercano a esta posición se encuentra asimismo Jürgen Habermas, para el que "los actuales movimientos de protesta ofrecen, por primera vez, la posibilidad de hacer entender, también en Alemania, la desobediencia civil como elemento de una cultura política madura» ${ }^{19}$. Y ello pese a las discrepancias de fondo con la teoría contractualista de Rawls a la que acusa de no ofrecer las bases adecuadas de fundamentación. Pues, para Habermas, un contrato, en cuanto transacción entre los intereses de los contratantes, no puede tener en sí su propio fundamento. Por lo cual, él prefiere seguir la vía de la ética discursiva 20 .

17 Ibid., 97.

18 Ibid., 98.

19 J. Habermas, "La desobediencia civil", Leviatán 14 (1983), 99-111, cit., 101.

20 Me referí a ella en "La Escuela de Frankfurt: J. Habermas", en F. Val.espin (ed.), Historia de la teoria politica, VI, Alianza, Madrid, 1995, 219-258. 


\subsection{La racionalidad comunicativa y la ética del discurso}

Entroncando con la tradición del idealismo alemán (Kant y Hegel), que diferenciaban entre el entendimiento (Verstand) y la razón (Vernunft), Habermas distingue diversos tipos de racionalidad. Por imperante que haya sido en el desarrollo de la Modernidad, la racionalidad científico-técnica, que responde al interés por el control del mundo, no es la única, ni siquiera la primordial. Más importante es la racionalidad comunicativa, que no se rige tanto por la acción orientada al éxito cuanto por la comprensión intersubjetiva. En el caso de que se presenten conflictos acerca de afirmaciones de hecho o de la corrección de las normas que deben guiarnos, Habermas piensa que pueden ser resueltos discursivamente, si las diferentes pretensiones son sometidas a argumentación, pues cualquiera que argumente en serio está presuponiendo la posibilidad de llegar a entender al otro. Y esa discusión desembocaría en un consenso, en la medida en que los participantes en la misma se ajustasen a la situación ideal de habla, que sería aquélla en la que todos los afectados gozasen de una posición simétrica para defender argumentativamente sus intereses y ver cuáles de ellos son generalizables, de forma que el consenso resultante estuviera exento de coacción y sólo se debiera a la fuerza del mejor argumento. Aunque los diálogos humanos no responden habitualmente a esos requisitos, Habermas no deja de insistir en que el proceso de la comunicación opera ineviablemente con la presuposición de llegar a entender al otro. Presuposición que se puede crítica, contrafácticamente, anticipar.

Y así, según Habermas, tal procedimiento podría ayudar a resolver un problema que ya estaba presente en Rousseau: cómo la ley, válida para todos, no ha de resultar de la imposición de nadie en particular, sino que ha de emanar de la autolegislación de cada cual, de manera que el sometimiento a la ley no sea sino expresión de la propia libertad, ya que, en palabras del propio Rousseau, «la obediencia a la ley que uno se ha prescrito es libertad" ${ }^{21}$. Problema que vuelve a aparecer en Kant, como tensión entre la universalidad de la legislación moral y la autonomía de cada hombre, y que Habermas quiere canalizar a través de la trasposición dialógica del imperativo categórico kantiano. Si, en la primera de sus formulaciones, éste ordenaba obrar «sólo según una máxima tal que puedas querer al mismo tiempo que se torne ley universal", dicha transpo-

21 J. J. Rousseau, El Contrato social, I, 8, trad. e introd. de M. Armiño, Alianza, Madrid, $1980,27-28$. 
sición -en palabras de Th. McCarthy, que Habermas ha hecho suyas- prescribiría: «Más que atribuir como válida a todos los demás cualquier máxima que yo pueda querer que se convierta en una ley universal, tengo que someter mi máxima a todos los otros con el fin de examinar discursivamente su pretensión de universalidad. El énfasis se desplaza de lo que cada cual pueda querer sin contradicción que se convierta en una ley universal a lo que todos pueden acordar que se convierta en una norma universal» 22

Normatividad común legislada por todos los implicados, que no tiene por qué atentar, sin embargo, contra el pluralismo de formas de vida o las diferentes ideas del Bien y la Felicidad. Más bien, sería en el marco trazado por ese proceso de formación discursiva de la voluntad común, dentro del que las aspiraciones plurales podrían afirmarse. Con lo que Habermas trata de responder, de nuevo, al reto al que veíamos se enfrentaba Rawls.

\subsection{La desobediencia civil «entre la legalidad y la legitimidad»}

Pero, de nuevo también aquí, se plantea un conflicto similar. Pues, si la más o menos adecuada traducción política de ese procedimiento acaba por resolverse en algún tipo de regla de las mayorías, hemos de preguntarnos qué lugar cabe para el desobediente civil o, sencillamente, el disidente.

Pese a que el escrito sobre la desobediencia civil es más bien coyuntural -a propósito de los debates suscitados en Alemania en la década de los ochenta, con ocasión de la instalación de los euromisiles-, el propio Habermas no ha dejado de llamar la atención sobre eel tema del sentido y de los límites de la regla de la mayoría. ¿Por qué debe permitirse - se pregunta- la desobediencia civil en el estado democrático de derecho" ${ }^{23}$. Tras recoger gran parte de los planteamientos que, al respecto, había elaborado Rawls en Una teoría de la justicia, Habermas esboza una respuesta que, en consonancia con el conjunto de su construcción, insiste en que las normas, en un estado de derecho, han de ser acatadas porque expresan «un interés potencialmente universal» 24 . Pero, como

22 Th. MCCARTHX, La teoria critica de J. Habermas, trad. de M. Jiménez Redondo, Tecnos, Madrid, 1987, 377. La referencia de Habermas a la formulación de McCarthy en "Ética del discurso", en Conciencia moral y acción comunicativa, trad. de R. G. ${ }^{2}$ Cotarelo, Península, Barcelona, 1985, 57-134, cit., 88.

23 J. HABERMAS, «La desobediencia civil», cit., 103.

24 Ibid. 
«la realización de principios constitucionales pretenciosos, con contrapartidas universalizantes, es un proceso a largo plazon, la desobediencia civil no es algo puramente anormal en los estados democráticos, sino «un caso normal que siempre volverá a aparecer [...]. Los atentados civiles contra las normas son experimentos de base moral, sin los cuales una república firme no puede obtener de sus ciudadanos ni la capacidad innovadora ni la fe en la legitimación” 25 .

El estado democrático de derecho «no basa su legitimidad en una pura legalidad" 26 , y es por ello por lo que "la desobediencia civil debe quedar sopesada entre legitimidad y legalidad"27. Como Rawls, Habermas estima que la desobediencia civil ha de ejercerse para llamar la atención de la mayoría en vistas a un consenso constitucional, sin que quepa reemplazar éste por creencias personales: la desobediencia civil use sabe obligada al consenso constitucional y no debe ser reemplazada por el establecimiento de creencias y certezas personales" ${ }^{28}$. Y es que, sin una pretensión universalizable, esa desobediencia corre el riesgo de desembocar en el vacío, al menos por lo que a la argumentación pública hace, ya que «los locos de hoy no son siempre los héroes de mañana” ${ }^{29}$.

Por otra parte, sin embargo, el legalismo autoritario, que trata de difundir el estribillo de que "la resistencia no violenta es violencia" - como, en la época en que Habermas escribía su artículo, hacían los señores Zimmerman y Spranger, el dúo bávaro del Gobierno Federal, al que se refiere al comienzo del mismo-, ese legalismo que abomina de toda ambigüedad, en realidad, «reniega de la sustancia humana, de lo no-unívoco, precisamente ahí donde el estado democrático de derecho se nutre de esa sustancian ${ }^{30}$.

5. Ética y derecho: la polémica española en torno a la obediencia al Derecho

Con todo ello, lo que se pone de manifiesto es que buena parte del debate del que estamos tratando se subsume en otro más amplio, que afecta a las rela-

$\begin{array}{ll}25 & \text { Ibid., 104-105. } \\ 26 & \text { Ibid., } 103 . \\ 27 & \text { Ibid., 106. } \\ 28 & \text { Ibid., 106. } \\ 29 & \text { Ibid., } 105 . \\ 30 & \text { Ibid., } 110 .\end{array}$


ciones entre Ética y Derecho. Como indica F. Laporta en la valiosa y apretada síntesis que recientemente ha realizado, esas tensiones se pueden situar entre los intentos de escisión más o menos radical y aquellos acercamientos que, sin confundir ambas esferas, oscilan, a su vez, entre el propósito de "legalizar la moral" o, a la inversa, el de «moralizar el derecho» ${ }^{31}$. De esa problemática sólo recogeré, por afectar más directamente a nuestro tema, la cuestión de la obediencia al derecho, siguiendo sobre todo el trabajo del profesor Felipe González Vicén, que ha dado lugar a una amplia polémica en el panorama español.

\subsection{Las tesis de González Vicén}

En efecto, en su artículo «La obediencia al derecho» 32 , el recientemente fallecido profesor Felipe González Vicén, Catedrático de Filosofía del Derecho en la Universidad de La Laguna, se planteaba el por qué de la obediencia jurídica, pero teniendo cuidado en distinguir tres planos posibles de cuestionamiento: uno, al que podríamos llamar explicativo, indagaría las causas que llevan a un individuo o grupo de individuos a esa obediencia. Otro, al que podríamos llamar motivacional, sustituiría, en realidad, el por qué por un para qué, la indagación de las causas por la de la finalidad. Pero habría un tercero, que es el que a González Vicén le interesa primordialmente, que no pregunta ni por las causas ni por los fines, sino por las razones que se pueden aducir para dicha obediencia, y que se sitúa, pues, en un plano de justificación filosófica de la misma.

Sin pretender resumir todos los pormenores de su argumentación, conviene destacar algunos puntos de la misma, antes de exponer su tesis. $Y$ lo primero, sería rechazar algunas de las teorías que se han propuesto clásicamente como respuesta al problema, pero que distan de ser una respuesta satisfactoria. Entre ellas, la apelación al «derecho de la fuerza" ha contado con muy antiguos defensores, que se remontan, por lo menos, a los sofistas. González Vicén recuerda la argumentación de Calicles en el Gorgias de Platón, similar a la de Trasímaco en el libro I de la República. Ahí Trasímaco trata de defender que «lo justo es lo que conviene al más fuerten $y$, cuando es invitado por Sócrates a acla-

31 F. LAPORTA, "Ética y Derecho en el pensamiento contemporáneo", en V. CAMPS (ed.), Historia de la ética, III, Crítica, Barcelona, 1989, 221-295.

32 F. GonzAlez VICÉn, "La obediencia al Derecho", en Estudios de Filosofia del Derecho, Universidad de La Laguna, La Laguna, 1979, 365-398. 
rar su posición, responde diciendo que eso es lo que sucede en todas partes, con independencia del tipo de gobierno:

Cada gobierno implanta las leyes en vista de lo que es conveniente para el: la democracia, leyes democráticas; la tiranía, leyes tiránicas, y así las demás. Una vez implantadas, manifiestan que lo que conviene a los gobernantes es justo para los gobernados, y al que se aparta de esto lo castigan por infringir las leyes y obrar injustamente. Esto, mi buen amigo, es lo que quiero decir; que en todos los Estados es justo lo mismo: lo que conviene al gobierno establecido, que es sin duda el que tiene la fuerza, de modo tal que, para quien razone correctamente, es justo lo mismo en todos lados, lo que conviene al más fuerte ${ }^{33}$.

Pero se advierte pronto la disparidad entre la pregunta que se formulaba y el tipo de respuesta que se da, por no situarse ambas en el mismo nivel. La respuesta de Trasímaco opera en el plano descriptivo, mientras que la pregunta de Sócrates trataba de alzarse al campo de lo normativo. Como el propio González Vicén señala, «la teoría del 'derecho del más fuerte' no es, pese a sus formulaciones, una teoría de la obligatoriedad, no se mueve siquiera en el ámbito del deber ser, sino sólo en el mundo de los hechos» ${ }^{34}$. Y, tras siglos de haberse renovado argumentos similares, Rousseau tratará, en el capítulo $3 .^{\circ}$ del Libro I de El Contrato social, de erradicar semejantes planteamientos:

La fuerza es un poder físico; no veo qué moralidad puede resultar de sus efectos. Ceder a la fuerza es un acto de necesidad, no de voluntad; es todo lo más un acto de prudencia. ¿En qué sentido podrá ser un deber? [...]. Esta palabra de derecho nada añade a la fuerza; aquí no significa nada en absoluto. Obedeced a los poderes. Si esto quiere decir ceded a la fuerza, el precepto es bueno, pero superfluo: respondo de que nunca será violado [...]. Convengamos, pues que fuerza no hace derecho 35 .

Por su parte, el iusnaturalismo opera con una idea de "naturaleza humana" que sólo es viable cuando hay una visión del mundo más o menos unificada (así, en la polis griega o en el Occidente medieval), que permite hacer pasar una determinada configuración histórica por un presunto orden natural. Pero, por lo que a nuestra historia se refiere, esa posibilidad saltó hecha pedazos con las

33 Platón, República, 338e-339a, trad. de C. Eggers, Gredos, Madrid, 1986, 77.

34 F. GONZALEZ VICEN, "La obediencia al Derecho", cit., 368.

35 J. J. Rousseau, El Contrato social, I, 3, ed. cit., 13-14. 
devastadoras guerras de religión de comienzos del mundo moderno. A partir de entonces, se sucederán diversas teorías que tratan de cimentar la inviolabilidad del Derecho en la seguridad jurídica que proporciona. Pero, para González Vicén, tras este esquema formal, siempre hay determinados valores materiales que son los que se consideran sagrados: La seguridad jurídica hace posible la realidad de ciertos valores que, ellos sí, son tenidos por esenciales para la vida en sociedad. $O$ dicho más precisamente: la seguridad jurídica es el modo formal necesario para que el Derecho haga reales en la convivencia un cierto sistema de valores. Es el gran esquema que se halla siempre en el fondo de las diversas teorías en las que la seguridad jurídica se nos presenta como fundamento de la obediencia al Derecho. La 'paz', la conservación de la vida, la autonomía de la persona, la consecución del placer, el libre juego económico son, según las doctrinas, los valores supremos y constitutivos de la vida social, valores que el Derecho tiene que hacer reales en la historia, mientras que la seguridad jurídica representa sólo la condición para esta realización ${ }^{36}$.

González Vicén no considera el Derecho como un orden intemporal y universal, sino como algo de naturaleza histórico-social, como "un instrumento técnico de dominación de las clases y de los grupos sociales" ${ }^{37}$, que no puede evitar la contradicción, denunciada por Marx, entre su pretensión de validez general y ser expresión de intereses muy determinados de una situación de poder.

Por lo demás, si tomamos la expresión "obligación» no en el sentido de seguir un esquema de conducta, so pena de incurrir en determinadas sanciones, sino en su sentido riguroso de representar una "exigencia absoluta»; esto es, si la entendemos no como fruto de un imperativo hipotético, que sólo vale si admitimos la condición, sino categórico o incondicionado; en resumen, si la entendemos en su sentido ético, sólo nos podemos referir a los imperativos de la conciencia ética individual y, por tanto, podemos afirmar que «no hay 'obligación' de obedecer al Derecho, si se toma la palabra 'obligación' en su sentido estricto, es decir, en su sentido ético [...]. Más aún, en tanto que orden heterónomo y coactivo, el Derecho no puede crear obligaciones, porque el concepto de obligación y el de un imperativo procedente de una voluntad ajena y revestido de coacción son términos contradictorios. 38

36 F. GONZALLZ VICEN, «La obediencia al Derecho», cit., 383.

37 Ibid., 386-387.

$38 \quad$ Ibid., 386. 
Esto no quiere decir, advierte González Vicén, que no haya ningún tipo de fudamento para obedecer al Derecho, como pueden serlo la certeza de las relaciones humanas en la convivencia, o el cumplimiento de las exigencias de una sociedad organizada de cuyas ventajas también gozamos. Pero, asimismo, es preciso resaltar que esos posibles fundamentos no constituyen una obligación ética: «Si un derecho entra en colisión con la exigencia absoluta de la obligación moral, este Derecho carece de vinculatoriedad y debe ser desobedecido. O dicho con otras palabras: mientras que no hay un fundamento ético para la obediencia al Derecho, si hay un fundamento ético absoluto para su desobediencia» 39 .

\subsection{Javier Muguerza y el imperativo de la disidencia}

Como decíamos, las tesis de González Vicén han desatado una amplia polémica, de la que ha hecho un sintético balance Juan Ramón del Páramo ${ }^{40}$. Sin seguir todos sus desarrollos, me detendré algo más en la respuesta que suscitó por parte de Elías Díaz y en la posterior intervención de Javier Muguerza. En su obra De la maldad estatal y la soberanía popular, E. Díaz admitía la segunda parte de la proposición de González Vicén, aunque con matices. "Discrepo, en cambio - añadía - de la primera parte de tal proposición, pues en mi opinión 'sí puede haber un fundamento ético para la obediencia al Derecho', lo mismo - y el mismo- que puede haberlo para su desobediencia: es decir, la concordancia o discrepancia de fondo entre normas jurídicas y normas éticas o, para decirlo al modo (no exento de riesgos) de González Vicén, la concordancia o discrepancia entre el Derecho y la conciencia ética individual" 41 . Y en ese punto de vista volvía a insistir en su libro de 1990 Ética contra política ${ }^{42}$, pues, para él, el Derecho no es solamente un instrumento de clase, sino algo que pretende revestir validez y obligatoriedad para toda la sociedad, siempre que venga sancionado por la soberanía popular y la regla de las mayorías. Lo cual no quiere decir que éste sea un orden perfecto, puesto que puede ser sometido al examen de una más exigente moralidad crítica. Pero, en cualquier caso, habría que

39 Ibid., 388.

40 J. R. DEL PÁRAMO, "Obediencia al Derecho: revisión de una polémica", Isegoria, 2 (1990), 153-161.

41 E. DiAZ, De la maldad estatal y la soberania popular, Debate, Madrid, 1984, 80.

42 E. DiAZ, Etica contra politica. Los intelectuales y el poder, Centro de Estudios Constitucionales, Madrid, 1990, especialmente 40-53. 
evitar tanto «el apriorismo 'idealista' y elitista de una ética contra política (contra toda política, incluida la política democrática)" cuanto "el apriorismo 'realista' y oportunista que a toda costa quiere alejar, y cuanto más mejor, a la política de la étican ${ }^{43}$.

En ese debate ha terciado Javier Muguerza, que, pese a algunos matices, se muestra más cercano a la posición de González Vicén que a la de Elías Díaz. Pero, en realidad, tras partir de la "polémica doméstica», J. Muguerza pasa a considerar las propuestas que, respecto a esta cuestión en particular y respecto a las relaciones entre Ética y Derecho en general, pueden deducirse de los planteamientos de autores como J. Rawls o J. Habermas, que aquí hemos examinado también. J. Muguerza comparte con Habermas el reproche que veíamos éste le hacía a Rawls de déficit de fundamentación de su teoría «neocontractualista». Pero, pese a ello, estima que, aunque las cuestiones de fundamentación no se pueden obviar, quizá no pueden acabar de responderse. Y por eso prefiere preguntarse más por los límites de la ética discursiva que por sus últimos fundamentos.

Esos límites serían dos: por un lado, la "condición humana", que no es una categoría ontológica (como lo sería la supuesta "naturaleza humana») sino moral. Por otro, la conciencia ética individual: sólo los individuos son capaces de actuar moralmente y, por tanto, ellos acaparan todo el protagonismo de la Ética. Por lo cual, el posible fundamento de la Ética habría de girar no tanto en torno a la primera formulación del imperativo categórico kantiano, o imperativo "de la universalidad", sino en torno a la segunda, según la cual "hemos de tomar a la humanidad, en nosotros mismos y en los demás, siempre como un fin y no como un mero medio". Imperativo que él gusta de denominar imperativo de la disidencia, porque más que decirnos cómo hemos de obrar, en realidad lo que nos dice es cómo no hemos de hacerlo, a saber: utilizando a los hombres como simples medios. Un imperativo de "contenido negativo" que lo que fundamenta, ante todo, es el derecho a decir "no»: Ese imperativo, en efecto, reviste

un carácter primordialmente 'negativo' y, antes que fundamentar la obligación de obedecer ninguna regla, su cometido es el de autorizar a desobedecer cualquier regla que el individuo crea en conciencia que contradice aquel principio. Esto es, lo que en definitiva fundamenta dicho imperativo es el

\footnotetext{
43 Ibid., 51.
} 
derecho a decir "No", y de ahí que lo más apropiado sea llamarle, como opino que merece ser llamado, el imperativo de la disidencia 44 .

Desde ese planteamiento, entonces, el papel de la desobediencia no es el de imponer a una colectividad, que ha de tomar sus propias decisiones, los puntos de vista del individuo desobediente a los acuerdos de la mayoría. Pero, por abrumadora que esa mayoría fuere, nunca estará legitimada para imponerse al individuo en todo aquéllo que éste estime que va contra los principios de su conciencia:

Desde la perspectiva ética del individualismo que he estado tratando de proponer no se desprende, pues no faltaba más, que un individuo pueda nunca imponer legítimamente a una comunidad la adopción de un acuerdo que requiera de la decisión colectiva, sino sólo que el individuo se halla legitimado para desobedecer cualquier acuerdo o decisión colectiva que atente - según el dictado de su conciencia - contra la condición humana [...]. La invocación de la desobediencia ética no podría servir nunca de pretexto para llevar al Ejército al poder contra la voluntad mayoritaria, pero podría, en cambio, servir para oponerse a los desmanes de cualquier régimen político, aun cuando dicho régimen no sea una dictadura y se apoye en la aquiescencia de la mayoría. Pues, por abrumadora que sea esa mayoría, también los regímenes democráticos son capaces - lo estamos viendo cada día- de cometer desmanes ${ }^{45}$.

Es decir, la regla de las mayorías puede servir como procedimiento de decisión política, pero ha de respetar una esfera de libertad del individuo que ningún poder puede sobrepasar y, en caso de hacerlo, el individuo estará legitimado para desobedecerlo. Pues la decisión mayoritaria también puede ser injusta.

En realidad, este problema ya estaba presente en Rousseau, cuando trataba de distinguir entre la voluntad de todos (que podría no ser sino el conjunto de voluntades guiadas por intereses particulares) y la voluntad general, cuyo objeto no era particular, sino general: el bien común. Con todo, aunque se entiende la distinción hecha por Rousseau, él mismo no parece haber acabado de aclarar cómo se encuentra esa voluntad general y cómo se expresa. Y, pese a que probablemente no contaba entre sus propósitos, algunas de sus páginas han podido dar pie — con razón o sin ella- para ese despotismo, que a él tanto le de-

44 J. MUGUERZA, «La obediencia al Derecho y el imperativo de la disidencia (Una intrusión en un debate)", Sistema, 70 (1986), 27-40, cit., 37.

45 Ibid., 39. 
sagradaba, pero que no deja de resonar en algunas de sus expresiones, como aquella terrorífica, según la cual: «quien rehúse obedecer a la voluntad general será obligado a ello por todo el cuerpo: lo cual no significa sino que se le forzará a ser libre» 46 .

Y quizá, al hilo de esos problemas, podemos recordar que democracia y liberalismo responden — como subrayó Ortega - a cuestiones distintas: la democracia se pregunta por el sujeto del poder público y responde que es el pueblo. El liberalismo pregunta por sus limites y responde que hay en el individuo una esfera inviolable, que el poder ha de respetar. De forma que, en el extremo, cabría la posibilidad de un régimen democrático nada liberal o, a la inversa, la de un régimen liberal nada democrático, aunque, en el desarrollo de la historia occidental contemporánea, democracia y liberalismo hayan sido -al menos como ideal- asociados en los sistemas liberal-democráticos.

Y es hablando de éstos, precisamente, donde, pese a todo, se plantea la cuestión de la desobediencia. Pues, a su vez, las competencias del poder y los límites que debe respetar vienen a ser fijados en los principios constitucionales y otras leyes emanadas del poder legislativo, democráticamente elegido. Y puede darse el caso de que alguien, pese a reconocer sus deberes de cooperación para la sociedad en la que vive, disienta, en ciertos puntos fundamentales, de los acuerdos adoptados por la mayoría. La tesis de González Vicén y Javier Muguerza es que, en ese caso, no tiene ningún deber de seguir esos acuerdos, sino más bien, de acuerdo consigo mismo, el deber de desobedecerlos, por más que, normalmente, ello le acarree las sanciones y castigos previstos por la ley, hasta el momento en que esa ley sea modificada, si es que algún día lo es.

Desobediencia ética que, tanto uno como otro, se encargan de diferenciar de la desobediencia civil. Pues aunque ésta suela estar inspirada por motivos éticos y, por su parte, la desobediencia ética puede dar lugar a movimientos de desobediencia civil, en realidad, "la desobediencia ética no persigue, por definición, ninguna finalidad concreta y no es, por eso, tampoco susceptible de organización, no busca medios para su eficacia. Su esencia se encuentra en el enfrentamiento de la existencia individual consigo misma [...]. Lo esencial es aquí la adhesión inquebrantable a un imperativo moral, independientemente de cuáles sean sus consecuencias» 47 .

46 J. J. Rousseau, El Contrato sociah I, 8, ed. cit., 26.

47 F. GONZALEZ VICÉN, «La obediencia al Derecho", cit., 392-393. 


\subsection{Un caso de la justicia española: la absolución de un insumiso}

Un caso de la justicia española que, en su día, llamó ampliamente la atención de los medios de comunicación fue la absolución del insumiso al servicio militar y a la prestación social sustitutoria Ińaki Arredondo García, por parte del titular del Juzgado de lo Penal número 4 de Madrid, José Luis Calvo Cabello. La sentencia - que más tarde sería recurrida - tuvo tanta resonancia por ser la primera en la que no sólo se rebajaba notablemente la pena prevista, sino que era absolutoria. La decisión fue agriamente criticada por un amplio sector de profesores universitarios, partidos políticos y por el, a la sazón, ministro de Justicia, Tomás de la Quadra. Para Javier Tusell «los insumisos son personas que se autodefinen así pero que más merecerían el calificativo de insolidarios» ${ }^{48}$. Manuel Jiménez de Parga pensaba que "con esta orientación, regresaríamos al estado de naturaleza" 49, declarando que el gran insumiso había sido el juez, al que Fernando Savater no dudaba en calificar de "paradojico" (aunque, quizá, la única paradoja del juez Calvo Cabello, no estuviera sino en sus apellidos), viendo muy pocos motivos para alegrarse de la sentencia, «salvo el de hacer ruido sobre cuestiones que siempre está bien que se aireen, aunque sea a golpe de disparate» 50 .

Lo cierto es que el juez había alzado una sólida argumentación en la que probaba la indudable honradez del insumiso - prolongada colaboración con organizaciones pacifistas y de ayuda al Tercer Mundo; reconocimiento por parte de figuras morales de prestigio, como el obispo sudafricano y Premio Nobel de la Paz, Desmond Tutú, etc.- y trataba de apelar a principios constitucionales como la libertad de conciencia, para evitar la condena prevista por el Código Penal, que, en ese caso, en su opinión, provocaría una injusticia. En la disyuntiva «individuo o sociedad, persona o Estadom, el juez optaba —en función del margen de ambigüedad que pensaba que las leyes le ofrecían - por «la libertad de conciencia y la dignidad de las personas", estimando que el Sr. Arredondo incumplía, desde luego, un deber, pero "por imperativo de su conciencia, de una conciencia auténtica, adquirida no en virtud de ciertas conveniencias, sino con base en su formación religiosa y en constante educación de sus potencias morales". Aducía asimismo el testimonio del propio insumiso en el juicio, en el

J. TusELl, "Grietas en el Estado de Derecho", Diario 16, 15-III-92.

49 M. JiméneZ de PARGA, "La conciencia y la ley", La Vanguardia, 15-III-92.

so F. SAVATER, «Leyes y conciencias", El Pats, 29-III-92. 
que había declarado su disposición a acatar la eventual pena que se le impusiera y no recurrirla ${ }^{51}$.

Lo primero que se puede deducir de casos como éste, es que Ética y Derecho no parecen poder correr siempre de manera paralela y concorde. Si, dada la veracidad que el testimonio vital del insumiso manifestaba, su actitud parece, desde un punto de vista ético, irreprochable, es más dudosa la decisión judicial.

No, desde luego, para que diera lugar al tipo de manifestaciones que provocó en el coro de acusadores del juez, como si eso supusiera volver a la guerra de todos contra todos, a que cada individuo se volviera un egosita insolidario y tratara de imponer su visión de las cosas a los demás, según lo cual, hasta el tráfico sería anárquico (J. Tusell). Por otra parte, la sentencia no era tan absurda. Ya antes, otros jueces habían rebajado considerablemente la pena por motivos similares. Y poco después, otros la han repetido, como expresión de una sensibilidad moral, que ha llevado a la modificación del castigo previsto ante el delito de insumisión en el Código Penal que acaba de entrar en vigor (aunque quizá la inhabilitación durante doce años para desempeñar cualquier puesto en la Administración, sea todavia peor). Cambio de sensibilidad que se refleja asimismo en el proyecto de suprimir el servicio militar obligatorio, si bien esta supresión tal vez deba más a las condiciones técnicas de la guerra moderna que no a la sensibilidad moral y, por otra parte, un ejército profesional conlleva asimismo serios problemas, de los cuales no es el menor el de preservar la conciencia de los honrados, satisfechos y pacíficos ciudadanos, que, eso sí, encargan el trabajo sucio a otros, fácilmente reclutables entre la masa de marginados.

Sin entrar en todas las ramificaciones del debate, no se puede olvidar, en todo caso, que el poder judicial no es el encargado de elaborar leyes. Y sería contraproducente que funcionarios u órganos no elegidos democráticamente para esa función se pusieran a realizarla. Pero también es cierto que, a veces, la legislación deja zonas de penumbra, zonas ambiguas en las que el juez habrá de atender a la sensibilidad social, a las circunstancias del caso, a la interpretación que puede dar a normas que se oponen a otras normas o principios. El juez no es sencillamente una máquina que aplica la ley, sino una persona que juzga de

51 Cfr. El Pats, 7-III-92.

52 Cfr. J. Muguerza, «El tribunal de la conciencia y la conciencia del tribunal (Una reflexión ético-jurídica sobre la ley y la conciencia), Doxa, 15-16 (1994), 535-559. 
acuerdo con la ley. Pero ésta siempre deja un margen de interpretación 52 . Ya Aristóteles señalaba, al hablar de la equidad, que «tal es la naturaleza de lo equitativo: una corrección de la ley en la medida en que su universalidad la deja incompleta", siendo equitativo "aquel que, apartándose de la estricta justicia y de sus peores rigores, sabe ceder, aunque tiene la ley de su lado. Tal es el hombre equitativo, y este modo de ser es la equidad, que es una clase de justicia, y no un modo de ser diferente" 53 .

\section{Otras cuestiones}

No querría terminar sin añadir alguna cuestión más a las ya planteadas. Al hablar de la sentencia absolutoria del insumiso Iñaki Arredondo, veíamos que el juez había tratado de apelar a los principios constitucionales, como parte de su argumentación y, probablemente, en cuanto juez, no podía hacer otra cosa. Pero, también señalamos que los caminos de la Ética y del Derecho no siempre corren paralelos. ¿Tendría el "desobediente civil» que apelar también siempre necesariamente a esos principios? Así parece entenderlo Rawls, al afirmar que la desobediencia civil legítima es uun dispositivo que tiende a hacerlo [al régimen constitucional] más firmemente juston ${ }^{54}$, o que «la mejor forma de entender la desobediencia civil en una sociedad democrática es como una apelación a los principios de justicia, a las condiciones fundamentales de la cooperación social voluntaria entre hombres libres, las cuales a los ojos de la comunidad en su conjunto se expresan en la constitución y guían su interpretación" 55 . Y por eso insistía en que, aunque el desobediente civil puede estar inspirado por principios religiosos o morales de muy diverso tipo, es mejor que apele a ese sentido de los principios constitucionales 56 .

Quizá, como él mismo indica, una revisión permanente de la Constitución, amenaza socavar ese mínimo de estabilidad que la convivencia social requiere. $\mathrm{Y}$, por otra parte, en sociedades plurales, la apelación a esos principios mutua-

53 ARISTÓTEles, Etica nicomáquea, 1137b25-1138a, trad. de J. Palli, Gredos, Madrid, 1985, 261-262 (subrayado mío).

54 J. RAwLS, "La justificación de la desobediencia civil», cit., 98.

55 Ibid., 95-96.

56 Sobre ello vuelve a insistir en El liberalismo politico, trad. de A. Domènech, Crítica, Barcelona, 1996, especialmente cap. VI ("La idea de una razón pública"), aptdo. 8 ("Los límites impuestos por la razón públican), pp. 282ss. 
mente compartidos ha de ser más entendible por el resto de los ciudadanos sobre los que se trata de llamar la atención con el acto desobediente. Sin embargo, habría que tener en cuenta también que los textos legales, constitución incluida, son hechura humana, fenómenos históricos, históricamente revisables: los acuerdos que un día pueden alcanzarse, tal vez, al cabo de un cierto tiempo, ya no se den, y, por tanto, tampoco los principos constitucionales han de considerarse inamovibles.

El disidente no habría de verse obligado, pues, a apelar necesariamente a esos principios, sino que puede hacerlo también a otros que crea, en conciencia, merecen ser escuchados. Qué duda cabe que la apelación a esas concepciones hace más difícil el "solapamiento" entre las visiones particulares del Bien, de grupos o individuos, para lograr normas universales de justicia que han de regirnos a todos. Pero también pudiera suceder, como de hecho en la historia tantas veces ha sucedido, que lo que en un determinado momento se consideran visiones particularistas a excluir de las normas públicas, acaban expresando un potencial universal mayor que el de esas normas que pretendían excluirlas. Quizá el disidente no logre ser escuchado y haya de sufrir, además del castigo previsto por la ley, la incomprensión de sus conciudadanos y quién sabe si la de una indefinida posteridad, cuyas razones él ya no podrá oir. Razones que, en ocasiones, le podrían haber hecho cambiar de opinión, ya que no está excluido que el disidente se equivoque. Como Habermas decía: "Los locos de hoy no siempre son los héroes de mañana". Pero las generaciones futuras sí podrán escuchar las suyas y tal vez abrirse a nuevos acuerdos y sensibilidades anegadas por el consenso presente. Consensos que, si pueden ayudar a evitar el fanatismo y la intolerancia de los que la historia ha dado tantas muestras, también pueden suponer, como recordaba González Vicén, la imposición de los intereses de determinados grupos o sociedades dominantes, bajo la pretensión de universalidad. Los locos de hoy no son siempre los héroes de mañana, pero también, en muchas ocasiones, el mañana ha recogido las pretensiones locas, excluidas hoy por los sensatos de turno.

El caso de Sócrates, con el que comenzábamos (un caso que, según lo que hemos visto, cabría calificar más de disidencia ética que de desobediencia civil) es un buen ejemplo de lo que decimos. Sobre todo, porque los riesgos de su firmeza los corrió ante todo el propio Sócrates, en vez de, como es más habitual, ser firmes en la aplicación de principios cuyos costes y riesgos los corren los demás. 